\title{
INDUÇÃO DO ENRAIZAMENTO DE REBENTOS DE AMORA - PRETA (Rubus ulmifolius) TRATADOS COM ÁCIDO INDOLILBUTÍRICO
}

\author{
PINTO, Calistene Aparecida ${ }^{1}$ \\ CARVALHO, Tereza Cristina $\mathrm{de}^{2}$
}

\begin{abstract}
RESUMO: O objetivo do presente trabalho foi avaliar o potencial de enraizamento de rebentos de amora - preta, influenciados pelo ácido indolilbutírico. Para a realização do ensaio foram utilizados rebentos de amora - preta de aproximadamente 10 centímetros de comprimento com diâmetros diferentes, obtidos na segunda quinzena de fevereiro de 2018. O delineamento experimental adotado foi o de blocos ao acaso, sendo que os rebentos de amora preta foram tratados com AIB (ácido indolilbutírico) a cinco concentrações, as quais correspondem a 0, 10, 20, 50 e $100 \mathrm{mg} \mathrm{L}{ }^{-1}$. Cada tratamento conteve quatro repetições, sendo que cada repetição, foi formada por 20 rebentos de amora - preta. Ao final de 87 dias de cultivo, os rebentos foram avaliados quanto à porcentagem de rebentos vivos e enraizados, mortos e vivos não enraizados, volume radicular $\left(\mathrm{mm}^{3}\right)$, área superficial específica $\left(\mathrm{mm}^{2}\right)$, comprimento total de raízes $(\mathrm{mm})$, diâmetro ponderado de raízes $(\mathrm{mm})$ e, massa fresca e seca radicular $(\mathrm{g})$. Concluiu - se que não houve efeito das concentrações de ácido indolilbutírico para porcentagem de rebentos de amora - preta viáveis, não viáveis e mortos, para comprimento total de raízes e para massa fresca e massa seca, e com o aumento das concentrações de AIB houve o decréscimo para as variáveis de volume, área superficial específica e diâmetro ponderado de raízes.
\end{abstract}

Palavras - chave: Rubus ulmifolius. Auxina. Propagação vegetativa.

\section{INDUCTION OF ROOTING OF BLACKBERRY (Rubus ulmifolius) SHOOTS TREATED WITH INDOLYLBUTYRIC ACID}

SUMMARY: The objective of the present work was to evaluate the rooting potential of blackberry shoots, influenced by indolylbutyric acid. For the test, blackberry shoots of approximately $10 \mathrm{~cm}$ in length with different diameters, obtained in the second fortnigh to February 2018 wereused. The experimental design was a randomized block design, with the blackberry saplings were treated with AIB (indolylbutyricacid) atfive concentrations, which correspondto $0,10,20,50$ and $100 \mathrm{mg} \mathrm{L}-1$. Each treatment contained four replicates, and each replicate was composed of 20 sprouts of blackberry. At theend of 87 day sof cultivation, shoots were evaluated for percentage of live and rooted shoots, dead and not rooted live, root volume $\left(\mathrm{mm}^{3}\right)$, specific surface area $\left(\mathrm{mm}^{2}\right)$, total root length $(\mathrm{mm})$, weighted diameter of roots $(\mathrm{mm})$ and, fresh and dry root pasta $(\mathrm{g})$. It was concluded that there was no effect of indolylbutyric acid concentrations on percentage of viable, non - viableanddead blackberry shoots for total root lengthand for fresh mass and drymass, and with the increase of IBA concentrations the decrease for the variables of volume, specific surface area and weighted root diameter.

Keywords: Rubus ulmifolius. Auxin. Vegetative propagation.

\section{INTRODUÇÃO}

A amora - preta (Rubus ulmifolius), também denominada de blackberry, pertencente à família Rosaceae, representa uma das mais relevantes frutíferas de clima temperado. Proveniente

\footnotetext{
${ }^{1}$ Graduanda de Engenharia agronômica pelo Centro de Ensino Superior dos Campos Gerais-CESCAGE.

${ }^{2}$ Eng. Agrônoma, Prof. ${ }^{a}$ Doutora do Centro de Ensino Superior dos Campos Gerais - CESCAGE. Rua Tomazina S/N, Ponta Grossa, PR, Brasil, 84030-900.
} 
do Hemisfério Norte, a amora - preta tem ganhado espaço no mercado, e também em estudos científicos no Brasil. Isto se deve especialmente ao aumento significativo da demanda por frutos pequenos e frescos, e ao incentivo do cultivo por parte da agricultura familiar, com a finalidade de fabricar produtos alternativos (ANTUNES, 2002).

A amora - preta é uma planta de hábito arbustivo assumindo porte ereto e rasteiro, sendo que as hastes podem ser também eretas ou prostradas sem ou com espinhos, (ANTUNES; RASSEIRA, 2004) e, suas raízes são pivotantes e perenes (CLARK; FINN, 2014). Classificada como planta pertencente à família Rosaceae, os frutos de amora derivam de um ovário com apenas um óvulo, logo, são monospérmicos, onde o fruto agregado forma - se diretamente pela união das paredes das drupas. Dessa forma, Antunes (2006) afirma que a amoreira - preta produz minidrupas que dão origem aos seus frutos agregados de coloração negra e de sabor adocicado a ácido.

A obtenção de novas plantas de amora - preta se dá especialmente, por propagação vegetativa. Para efetuar a produção mudas de amora - preta, são retirados órgãos vegetais de plantas matrizes como as estacas, os rebentos ou os perfilhos oriundos das linhas de plantio, os quais são induzidos ao enraizamento (WENDLING, 2003). Segundo Tchoundjeu et al. (2002), para a propagação vegetativa ocorrer com êxito, há diversos fatores entre eles: ao potencial de enraizamento, aos reguladores de crescimento, e a morfologia e maturação das estruturas utilizadas para a realização da técnica.

O enraizamento é uma das atividades fisiológicas de maior relevância na produção de mudas que ocorre de forma assexuada. É através deste mecanismo que sucede o início do desenvolvimento vegetativo da planta.

Contudo, como alternativa para a indução do enraizamento, pode - se utilizar o hormônio vegetal conhecido por auxina, sendo que dentre os sintéticos mais estudados destacam - se o ácido indolacético (AIA), o ácido indolilbutírico (AIB) e o ácido naftalenoacético (ANA) (KOMISSAROV, 1968 apud ANDRADE et al., 2007).

O grupo das auxinas é o de maior evidência no âmbito científico, sendo que as mesmas são sintetizadas em locais de rápida divisão celular como folhas jovens, gemas apicais, frutos em desenvolvimento e sementes (PEREIRA et al., 2012). De acordo Augusto; Biasi; Telles (2006), o AIB possui a propriedade de não causar fitotoxidade em concentrações moderadamente altas, e a atender positivamente uma gama de espécies.

No estudo realizado por Fischer et al. (2008), sobre o enraizamento de estacas semilenhosas de mirtilo em concentrações de AIB, observou - se que a concentração de $1000 \mathrm{mg} \mathrm{L}^{-1}$ propiciou maior porcentagem de estacas enraizadas, comparado a concentrações de 0, 2000 e $4000 \mathrm{mg} \mathrm{L}^{-1}$. Esses autores destacam que a utilização de hormônios como as auxinas podem proporcionar o enraizamento até determinadas concentrações, sendo que o efeito pode ser inibitório caso exceda o potencial que a planta é capaz de sintetizar.

Na literatura há muitas menções sobre estacas caulinares, radiculares e medianas com a utilização do AIB para a indução do enraizamento, visto que as respostas mais positivas são em estacas radiculares. Porém estudos com rebentos ainda são escassos.

Portanto, o objetivo do presente trabalho foi avaliar o potencial de enraizamento de rebentos de amora - preta, influenciados pelo ácido indolilbutírico.

\section{MATERIAL E MÉTODO}

O experimento foi conduzido nos Laboratórios de Fitopatologia e de Sementes do Centro de 
Ensino Superior dos Campos Gerais - CESCAGE, localizado na Fazenda Escola no município de Ponta Grossa - PR). O clima da região, segundo a classificação de Köppen é do tipo $\mathrm{Cfb}$, tendo como características ser subtropical úmido, com temperatura média anual de $18^{\circ} \mathrm{C}$ e precipitação média anual de aproximadamente $1.550 \mathrm{~mm}$ (ALVAREZ et al., 2013).

A coleta dos rebentos e a instalação do experimento ocorreram na segunda quinzena de fevereiro de 2018.

Para a realização do ensaio foram utilizados rebentos de amora - preta de aproximadamente 10 centímetros de comprimento com diâmetros diferentes, obtidos de plantas matrizes do cultivar Tupy. As plantas matrizes tinham um ano de idade desde o transplante, sendo cultivadas no pomar da Fazenda Escola CESCAGE. A coleta dos rebentos ocorreu no período da manhã, onde as condições climáticas eram de temperatura amena, sem a presença de intensa radiação solar e umidade relativa elevada. Os rebentos superficiais oriundos de 20 plantas foram retirados do solo com o auxílio de uma enxada e divididos com tesouras de poda, conforme o comprimento proposto.

O delineamento experimental adotado foi o de blocos ao acaso, sendo que os rebentos de amora - preta foram tratados submetidos a cinco concentrações do regulador vegetal ácido indolilbutírico (AIB), as quais correspondem a $0,10,20,50 \mathrm{e} 100 \mathrm{mg} \mathrm{L}^{-1}$. Cada tratamento conteve quatro repetições, sendo que cada repetição, foi formada por 20 rebentos de amora - preta.

Os rebentos foram transplantados em bandejas plásticas circulares sem células, com capacidade de 3 litros, equivalente a dimensão de $34 \times 23 \times 7 \mathrm{~cm}$. O substrato utilizado foi do tipo vermiculita, sendo que os rebentos foram depositados na posição horizontal a $3 \mathrm{~cm}$ de profundidade, como adotado para estacas radiculares de amora - preta por Campagnolo; Pio (2012).

Houve três aplicações da solução de AIB correspondentes aos tratamentos diretamente no substrato, sendo que a primeira ocorreu no dia do transplante, a segunda 10 dias após o transplante e, a terceira aplicação aos 20 dias após o transplante. Os rebentos foram mantidos em local coberto de orientação leste - oeste, com irrigação de 0,5 litro para cada bandeja, em intervalos regulares de 5 dias.

Ao final de 87 dias de cultivo, os rebentos foram retirados da vermiculita e avaliados quanto à: porcentagem de rebentos vivos e enraizados, mortos e vivos não enraizados. As raízes foram submetidas à leitura ótica por meio de fotografia e analisadas pelo programa SAFIRA (JORGE, 2008), para obtenção do volume radicular $\left(\mathrm{mm}^{3}\right)$, área superficial específica $\left(\mathrm{mm}^{2}\right)$, comprimento total de raízes $(\mathrm{mm})$ e diâmetro ponderado de raízes $(\mathrm{mm})$. Após estas análises, as raízes foram avaliadas quanto à massa fresca e massa seca radicular $(\mathrm{g})$.

Após efetuadas as avaliações em todas as variáveis, os resultados obtidos foram submetidos a análise estatística. Para isso, foi adotada a análise de variância pelo teste $\mathrm{F}$ e de regressão, sendo os modelos escolhidos com base no coeficiente de determinação e na sua significância. Para tanto, foi utilizado o programa estatístico para microcomputadores RStudio (2018).

\section{RESULTADO E DISCUSSÃO}

Os resultados obtidos através de análises referentes ao volume total radicular de rebentos de amora - preta, submetidos a concentrações de ácido indolilbutírico estão apresentados na Figura 1. 
Figura 1. Análise de volume total radicular de rebentos de amora - preta em função de concentrações de ácido indolilbutírico.

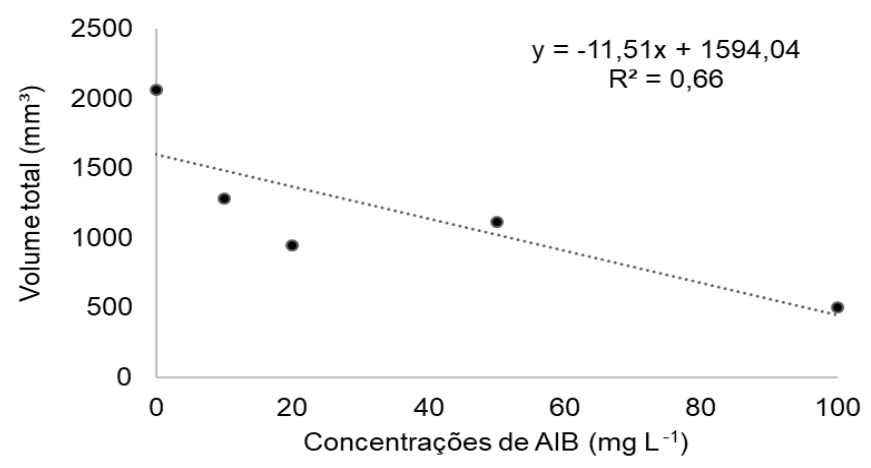

Analisando os dados obtidos, constatou - se que a concentração $0 \mathrm{mg} \mathrm{L}^{-1}$ de AIB proporcionou o maior valor para a variável de volume total de raízes de rebentos de amora - preta, sendo de 2058,58 $\mathrm{mm}^{3}$. A linha de tendência linear evidencia o comportamento descrente do efeito das concentrações de AIB nos rebentos, fazendo com que a concentração de $100 \mathrm{mg} \mathrm{L}^{-1}$ apresentasse o valor de 499,54 $\mathrm{mm}^{3}$. Assim, a medida que aumentou - se a dosagem de ácido indolilbutírico aplicados a rebentos de amora - preta, até a dose de $100 \mathrm{mg} \mathrm{L}^{-1}$, constatou decréscimo no volume total radicular.

Nos estudos realizados por Alexandre et al. (2014), foi possível analisar o efeito contrário das concentrações do ácido indolilbutírico no enraizamento de estacas de maracujazeiro silvestre (Passiflora mucronata Lam.). Verificou - se que a aplicação de AIB em concentrações acima de $250 \mathrm{mg} \mathrm{L}^{-1}$ e até $1000 \mathrm{mg} \mathrm{L}^{-1}$ proporcionaram maiores valores para volume das raízes, sendo $1,104 \mathrm{~cm}^{3}$ e $0,6817 \mathrm{~cm}^{3}$ para as formas de aplicação sólida e líquida, respectivamente.

Dias; Ono; Duarte Filho (2011) observaram que quando o AIB é aplicado em brotações de estacas radiculares de amora - preta, para a promoção do enraizamento das mesmas, as concentrações de 250 e $500 \mathrm{mg} \mathrm{L}^{-1}$ proporcionam maior desenvolvimento em volume do sistema radicular dessas estruturas.

Em estudo realizado por Alexandre et al. (2013) sobre o enraizamento adventício de estacas de maracujá - doce (Passiflora alata Curtis), verificou - se o efeito da ausência e presença do AIB. Foi constatado que para a variável de volume de raízes, a presença de $2000 \mathrm{mg} \mathrm{L}^{-1}$ e a ausência não houve diferença significativa em 10 dos 15 genótipos de maracujá - doce estudado. Os menores valores observados para volume de raízes foram de $1,30 \mathrm{~cm}^{3}$ e $1,63 \mathrm{~cm}^{3}$ para ausência e presença de AIB do mesmo genótipo. Já os maiores valores observados para volume de raízes foram de 7,25 e 9,25 cm³ para ausência e presença de AIB em genótipos diferentes.

Para a variável analisada de área superficial total radicular de rebentos de amora - preta, em função de concentrações de ácido indolilbutírico, os resultados estão expressos na Figura 2. 
Figura 2. Análise de área superficial total de raízes de rebentos de amora - preta em função de concentrações de ácido indolilbutírico.

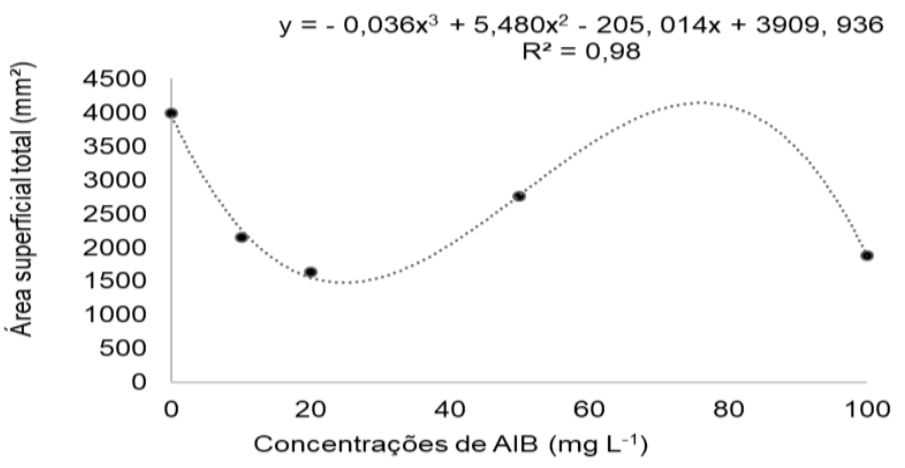

De acordo com a linha de função cúbica, é possível observar que os valores de área superficial total de raízes em rebentos de amora - preta, são expressivos na concentração de $0 \mathrm{mg} \mathrm{L}^{-1}$ onde obteve se 3989,24 $\mathrm{mm}^{2}$. Para concentrações de 10 e $20 \mathrm{mg} \mathrm{L}^{-1}$ de ácido indolilbutírico houve um decréscimo de área superficial de raízes de rebentos de amora - preta, apresentando $2151 \mathrm{~mm}^{2}$ e 1874,49 mm², respectivamente. Todavia, com o aumento da concentração de AIB para $50 \mathrm{mg} \mathrm{L}^{-1}$ houve acréscimo para essa variável sendo $2762,53 \mathrm{~mm}^{2}$, diminuindo para $1643,25 \mathrm{~mm}^{2}$ quando aplicado a concentração de 100 $m g L^{-1}$ de AIB.

Mesmo com avanço de pesquisas com o uso do AIB na indução do enraizamento de estruturas vegetativas de frutíferas, estudos que envolvem área superficial específica radicular ainda são escassos na literatura. Assim, Mauad (2004) estimando a ação de concentrações de ácido naftalenoacético (ANA) no enraizamento de estacas de azaléia (Rhododendron simsii Planch) sob substratos diferentes, constataram que houve um incremento de área superficial de raízes quando a percentagem de ANA aumentou nos substratos de húmus e areia. Em contrapartida, no substrato de casca de arroz, houve redução de área superficial radicular conforme houve o aumento da proporção de ANA. Desta forma, as concentrações de $0 \%$ e $7,5 \%$ apresentaram aproximadamente $200 \mathrm{~cm}^{2}$ e concentrações de $2,5 \%$ e $5 \%$ obtiveram $250 \mathrm{~cm}^{2}$ aproximadamente.

Em pesquisa realizada com a aplicação de ácido indolilbutírico e de boro em estacas herbáceas de azaléia, Bezerra (2017) observou um comportamento crescente de área superficial específica para raízes de azaléia, desde a concentração de $1000 \mathrm{mg} \mathrm{L}^{-1}$ até a de $3000 \mathrm{mg} \mathrm{L}^{-1}$, onde a concentração de $2000 \mathrm{mg} \mathrm{L}^{-}$ ${ }^{1}$ possibilitou os maiores valores para essa variável de aproximadamente $24 \mathrm{~cm}^{2}$.

Afonso et al. (2018) ao analisar a germinação in vitro de sementes de Tabernaemontana catharinensis e o enraizamento, sendo essas submetidas a inoculação de AIB, constataram o efeito do hormônio vegetal sobre a área superficial de raízes. Ao analisarem as concentrações, observaram que as estas promoveram um aumento significativo do sistema radicular, comparado com o tratamento controle (ausência de AIB), sendo que o tratamento de $0 \mathrm{mg} \mathrm{L}^{-1}$ apresentou $1,26 \mathrm{~cm}^{2}$ e o tratamento de maior concentração, sendo este de $4,0 \mathrm{mg} \mathrm{L}{ }^{-1}$ apresentou $2,68 \mathrm{~cm}^{2}$.

O comprimento radicular total foi outra propriedade analisada em rebentos de amora - preta, submetidos a concentrações de ácido indolilbutírico. Esses dados estão evidenciados na Tabela 1. 
Tabela 1. Análise comprimento radicular total de raízes de rebentos de amora - preta em função de concentrações de ácido indolilbutírico.

\begin{tabular}{cc}
\hline Concentrações de AIB $\left(\mathbf{m g ~ L}^{\mathbf{- 1}}\right)$ & Comprimento radicular total $(\mathbf{m m})$ \\
\hline 0 & 681,77 \\
10 & 444,59 \\
20 & 517,05 \\
50 & 823,11 \\
100 & 571,23 \\
\hline $\mathrm{CV}(\%)$ & $37,23^{\text {n.s. }}$ \\
\hline
\end{tabular}

Médias não diferem estatisticamente entre si pelo teste de regressão a 5\% de probabilidade.

Os dados obtidos para comprimento total radicular, não apresentaram significância estatística nas diferentes concentrações de ácido indolilbutírico aplicadas a rebentos de amora - preta.

Com isso, Oliveira et al. (2015), ao averiguar a utilização de concentrações de ácido indolilbutíricono enraizamento de miniestacas apicais de ipê - roxo (Handroanthus heptaphyllus Mattos)., notou que as estacas apresentaram projeção crescente em relação ao comprimento radicular. Conforme houve aumento da dose de AIB, o tratamento de dose $0 \mathrm{mg} \mathrm{L}^{-1}$ apresentou $60 \mathrm{~cm}$ e a dose de $8000 \mathrm{mg} \mathrm{L}^{-1}$ alcançou $80 \mathrm{~cm}$ de comprimento radicular.

Entretanto, no trabalho de Dias; Ono; Duarte Filho (2011), pesquisando o comportamento do AIB no estímulo do enraizamento de estacas de raízes de amoreira - preta (Rubus spp.), observaram que há o aumento do comprimento radicular. Portanto, quando é aplicada a concentração de $0 \mathrm{mg} \mathrm{L}^{-1}$, há o maior valor de comprimento radicular de $31,5 \mathrm{~cm}$ e a maior concentração de $4000 \mathrm{~L}^{-1}$ apresentou $15 \mathrm{~cm}$, sendo o menor valor para essa variável.

No experimento efetuado por Véras et al. (2018), é possível notar que as doses de AIB atuaram sobre o comprimento de raízes de umbu - cajazeira (Spondias sp.). A dose $2333 \mathrm{mg} \mathrm{L}^{-1}$ apresentou o valor mínimo para esse parâmetro de $0,99 \mathrm{~cm}$, e com o aumento progressivo, foi observado o maior comprimento, sendo de aproximadamente $4,2 \mathrm{~cm}$ na dose de $6000 \mathrm{mg} \mathrm{L}^{-1}$.

Os resultados obtidos através de análises referentes ao diâmetro ponderado de raízes de rebentos de amora - preta, submetidos a concentrações de ácido indolilbutírico estão apresentados na Figura 3.

Figura 3. Análise de diâmetro ponderado de raízes de rebentos de amora - preta em função de concentrações de ácido indolilbutírico.

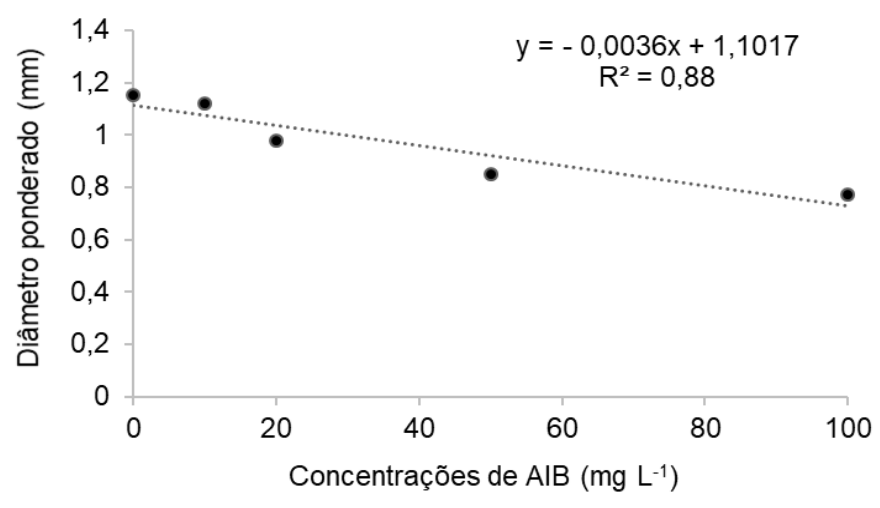

Verificando os dados obtidos na Figura 4, constatou - se que para diâmetro ponderado de raízes de rebentos de amora - preta, houve tendência linear decrescente sendo que as concentrações de maiores valores foram de $0 \mathrm{mg} \mathrm{L}^{-1}$ e $10 \mathrm{mg} \mathrm{L}^{-1}$ de 1,11 e $1,12 \mathrm{~mm}$, respectivamente. Já na concentração de $100 \mathrm{mg}$ 
$\mathrm{L}^{-1}$ houve decréscimo do diâmetro ponderado de raízes, totalizando o menor valor para a variável de 0,78 $\mathrm{mm}$.

Em pesquisas realizadas por Véras et al. (2018), notou - se que quando há o aumento das doses de AIB, há acréscimo do diâmetro de raízes de estacas de umbu - cajazeira. Os menores valores foram constatados nas doses de 3250 e $2500 \mathrm{mg} \mathrm{L}^{-1}$ com aproximadamente $1,3 \mathrm{~mm}$, e as maiores em 0 e 6000 $\mathrm{mg} \mathrm{L}^{-1}$ de aproximadamente $2,5 \mathrm{~mm}$.

Valmorbida et al. (2008), averiguaram que desde a utilização da dose 0 até a $5000 \mathrm{mg} \mathrm{L}^{-1}$, não houveram resultados significativos para o diâmetro de raízes de catigua (Trichilia catigua A. Juss), sendo que o maior e o menor valor foi de 0,20 e 0,25 , respectivamente.

Dias; Franco; Dias (1999) ao analisarem as concentrações de AIB de 0, 2000, 4000, 6000 e 8000 $\mathrm{mg} \mathrm{L}^{-1}$ na indução do enraizamento de estacas de leiteiro (Sapium glandulatum), observaram que não houve o efeito das mesmas. No tratamento com as doses de 0 e $2000 \mathrm{mg} \mathrm{L}^{-1}$ foram constatados os maiores diâmetros de raízes sendo de aproximadamente 3 e $4 \mathrm{~mm}$, respectivamente. Entretanto, para a concentração de $8000 \mathrm{mg} \mathrm{L}^{-1}$ foi observado o menor valor para diâmetro radicular, sendo de 2,6 mm, fazendo com que não haja diferenças significativas entre essas concentrações dispostas a estacas de leiteiro.

Na Tabela 2 estão expressos os resultados para os parâmetros de massa fresca e de massa seca de raízes de rebentos de amora - preta tratados com AIB.

Tabela 2. Massa fresca e massa seca de raízes de rebentos de amora - preta em função de concentrações de ácido indolilbutírico.

\begin{tabular}{ccc}
\hline $\begin{array}{c}\text { Concentrações de AIB } \\
\left(\mathbf{m g ~ L ~}^{-1}\right)\end{array}$ & Massa fresca de raízes $(\mathbf{g})$ & Massa seca de raízes $(\mathbf{g})$ \\
\hline 0 & 4,2730 & 2,8402 \\
10 & 6,1831 & 4,1180 \\
20 & 5,0289 & 3,1402 \\
50 & 5,6983 & 3,2740 \\
100 & 4,4499 & 2,8637 \\
\hline $\mathrm{CV}(\%)$ & $28,80^{\text {n.s. }}$ & $18,36^{\text {n.s. }}$ \\
\hline
\end{tabular}

Médias seguidas na coluna não diferem estatisticamente entre si a 5\% de probabilidade. ${ }^{\text {n.s. }}$ não significativo.

As informações representadas anteriormente sobre massa fresca e massa seca de raízes de rebentos de amora - preta, evidenciam que não há incremento do peso de raízes em relação a concentrações de AIB.

Em trabalho realizado por Paulus; Valmorbida; Paulus (2016), cujo objetivo foi avaliar a atuação do AIB na propagação por estaquia na cultura do alecrim em duas épocas do ano, constataram ação do AIB. Esses autores observaram maiores valores de massa fresca e massa seca de raízes nas estacas de alecrim, conforme houve o aumento das concentrações de AIB, onde o tratamento com $0 \mathrm{mg} \mathrm{L}^{-1}$ obteve aproximadamente $0,2 \mathrm{~g}$ por planta. Já a concentração de $2500 \mathrm{mg} \mathrm{L}^{-1}$ apresentou o maior valor de quase $0,7 \mathrm{~g}$ por planta, ligeiramente decrescendo na concentração de $3000 \mathrm{mg} \mathrm{L}^{-1} 0,5 \mathrm{~g}$ por planta.

Em contrapartida, Dias; Ono; Duarte Filho (2011) observaram que tanto para massa fresca quanto para massa seca de raízes de estacas radiculares de amora - preta, o tratamento de $250 \mathrm{mg} \mathrm{L}^{-1}$, proporcionou os melhores pesos, sendo $11,75 \mathrm{~g}$ para massa fresca e 9,33 g para massa seca. Seguido do tratamento também expressivo para essas variáveis de $500 \mathrm{mg} \mathrm{L}^{-1}$, o tratamento de $0 \mathrm{mg} \mathrm{L}^{-1}$ obteve melhores resultados que o tratamento com dose de $4000 \mathrm{mg} \mathrm{L}^{-1}$, sendo que este último2,82 $\mathrm{g}$ de massa fresca e $0,44 \mathrm{~g}$ de massa seca. 
Assim como no presente trabalho, Hussain et al. (2014), certificou - se que no seu experimento, as estacas de amora - preta submetidas aos tratamentos com AIB não apresentaram diferenças significativas em relação a massa seca de raízes. Verificou - se que os maiores e menores valores quantificados foram 0,5 e $0,4 \mathrm{~g}$, para massa seca nas dosagens de 0 e $2000 \mathrm{mg} \mathrm{L}^{-1}$.

O mesmo comportamento foi demonstrado para análises de rebentos vivos enraizados, rebentos vivos não enraizados e rebentos mortos de amora - preta. Os dados obtidos a partir desses fatores estão descritos na Tabela 3.

Tabela 3. Porcentagem de rebentos vivos enraizados, rebentos vivos não enraizados e rebentos mortos de amora - preta em função de concentrações de ácido indolilbutírico.

\begin{tabular}{cccc}
\hline $\begin{array}{c}\text { Concentrações de } \\
\text { AIB }\left(\mathbf{m g ~ L}^{-1}\right)\end{array}$ & $\begin{array}{c}\text { Rebentos vivos } \\
\text { enraizados }(\%)\end{array}$ & $\begin{array}{c}\text { Rebentos vivos não } \\
\text { enraizados }(\%)\end{array}$ & $\begin{array}{c}\text { Rebentos } \\
\text { mortos }(\%)\end{array}$ \\
\hline 0 & 83,75 & 12,50 & 3,75 \\
10 & 87,50 & 8,75 & 3,75 \\
20 & 88,75 & 7,50 & 3,75 \\
50 & 91,25 & 7,50 & 2,50 \\
100 & 83,75 & 10,00 & 6,25 \\
\hline CV $(\%)$ & $12,81^{\text {n.s. }}$ & $88,27^{\text {n.s. }}$ & $114,11^{\text {n.s. }}$ \\
\hline
\end{tabular}

Médias seguidas na coluna não diferem estatisticamente entre si a 5\% de probabilidade. ${ }^{\text {n.s. }}$ não significativo.

Averiguando os resultados obtidos na Tabela 3, sobre a viabilidade de rebentos de amora - preta, é possível notar que para as três análises realizadas, as concentrações de AIB não interferiram estatisticamente.

Contudo, Câmara et al. (2017) encontraram resultados com respostas significativas em relação a porcentagem de estacas enraizadas de amora - preta quando submetidas à concentrações de AIB. Com isso, constatou - se que houve a visualização de uma curva de tendência quadrática, sendo que o valor mínimo foi de aproximadamente $2,72 \%$ e o valor máximo de $2,88 \%$, nas concentrações de $0 \mathrm{mg} \mathrm{L}^{-1}$ e 1500 $\mathrm{mg} \mathrm{L}^{-1}$, sendo que na maior concentração $\left(2000 \mathrm{mg} \mathrm{L}^{-1}\right)$ obteve - se porcentagem de aproximadamente $2,76 \%$.

Acompanhando o enraizamento de estacas caulinares e radiculares de amora - preta coletadas em diferentes épocas, armazenadas a frio e tratadas com AIB, Campagnolo; Pio (2012) analisaram que estacas sem o tratamento de AIB alcançou a maior porcentagem de estacas enraizadas com $65 \%$ fazendo com que ao aumentar as concentrações, diminuiu os valores de porcentagens.

Já para estacas mortas de alecrim submetidas ao AIB, Paulus; Valmorbida; Paulus (2016), os resultados foram propícios, pois a maior porcentagem foi de $40 \%$ na concentração de $0 \mathrm{mg} \mathrm{L}^{-1}$ e de aproximadamente $5 \%$ e $20 \%$ nas concentrações de 2500 e $3000 \mathrm{mg} \mathrm{L}^{-1}$, respectivamente.

Assim como exposto pelos dados nesse trabalho, Trevisan et al. (2008), avaliando o efeito do ácido indolbutírico de estacas herbáceas em cultivares de mirtilo (Vaccinium sp.), verificaram que não houve diferença estatística. Em relação a percentagem de estacas enraizadas, o ácido indolilbutírico não interferiu nesta variável, mesmo com o aumento de concentrações de AIB desde 0 até $7500 \mathrm{mg} \mathrm{L}^{-1}$.

Ferreira et al. (2009), buscando o enraizamento de estacas semilenhosas de Sapium glandulatum, a partir do uso de concentrações de AIB em diferentes métodos de aplicação, testemunhou que em quando as estacas foram tratadas com 0,200 e $400 \mathrm{mg} \mathrm{L}^{-1}$ apresentaram os resultados mais propícios para porcentagem de estacas vivas não enraizadas e estacas mortas. Com o aumento das concentrações até 8000 $\mathrm{mg} \mathrm{L}^{-1}$ os resultados se apresentaram de forma decrescente, inviabilizando o uso de AIB para esses parâmetros. 


\section{CONCLUSÃO}

As concentrações de ácido indolilbutírico de $0,10,20,50$ e $100 \mathrm{mg} \mathrm{L}^{-1}$ não atuaram no enraizamento de rebentos de amora - preta.

O ácido indolilbutírico não interferiu em parâmetros como massa fresca e seca, e no comprimento radicular dos mesmos. Com o aumento das concentrações de AIB, houve o decréscimo para o volume, área superficial específica e diâmetro ponderado de raízes. $\mathrm{O}$ enraizamento de rebentos de amora - preta ocorre dentro da normalidade, sem diferenças significativas, mesmo sem a utilização do ácido indolilbutírico.

Não houve efeito das concentrações de ácido indolilbutírico para porcentagem de rebentos de amora - preta viáveis, não viáveis e mortos.

\section{REFERÊNCIAS}

AFONSO, M. V.et al.Germinação in vitro de sementes e parâmetros morfofisiológicos de microestacas de Tabernaemontana catharinensis A. DC. Iheringia, v. 73, n. 1, p.39-45, 2018.

ALEXANDRE, R. S.et al. Enraizamento adventício de estacas do maracujazeiro silvestre Passiflora mucronata Lam.: forma de veiculação e concentrações do ácido indol-3-butírico. Revista Ceres, v. 61, n. 4, p.567-571, 2014.

ALEXANDRE, R. S.et al. Enraizamento de estacas de genótipos de Passiflora alata Curtis em resposta a ausência e presença de ácido indol-3-butírico (AIB). Revista Ciências Agrárias, v. 56, n. 4, p.287-291, 2013.

ALVAREZ, C.A.et al. Köppen's climate classification map for Brazil. Meteorogische Zeitschrift. v. 22, n. 6, p. 711-728, 2013.

ANDRADE, R. A.et al. Propagação da amora - preta por estaquia utilizando ácido indolbutírico. Revista Caatinga, v. 20, n. 2, p.79-83, 2007.

ANTUNES, L.E.C. Amora-preta: Nova opção de cultivo no brasil. Ciência Rural, v. 32, n. 1, p.151-158, 2002.

ANTUNES, L.E.C.; RASSEIRA, M. do C.B. Aspectos técnicos da cultura da amora-preta. Pelotas: EMBRAPA, 2004. 49 p.

ANTUNES, L. E. C. Amora-preta (Rubus spp). Revista Brasileira de Fruticultura, v. 28, n. 3, p.339$558,2006$.

AUGUSTO, C. S. S.; BIASI, L. A.; TELLES, C. A. Enraizamento e aclimatização de plantas micropropagadas de amoreira-preta cv. Brazos. Revista Brasileira de Fruticultura, v. 28, n. 3, p.473476, 2006.

BEZERRA, A. K. D. Efeito do ácido indolbutírico, boro e armazenamento no enraizamento de estacas de azaleia cultivadas em vaso. 2017. 57 f. Tese (Doutorado) - Faculdade de Ciências Agrárias e Veterinárias - UNESP, Jaboticabal.

CÂMARA, F. M.M.et al. Tipos de estacas e concentrações de ácido indol-butírico (IBA) na propagação de amora (Morus nigra). Revista de La Facultad de Agronomía, v. 116, n. 2, p.187-191, 2017. 
CAMPAGNOLO, M. A.; PIO, R. Enraizamento de estacas caulinares e radiculares de cultivares de amoreira-preta coletadas em diferentes épocas, armazenadas a frio e tratadas com AIB. Ciência Rural, v. 42, n. 2, p.232-237, 2012.

CLARK, J. R.; FINN, C. E. Blackberry cult ivat ion in the world. Revista Brasileira de Fruticultura, v. 36, n. 1, p.46-57, 2014.

DIAS, R. M. S. L.; FRANCO, E. T. H.; DIAS, C. A. Enraizamento de estacas de diferentes diâmetros em Platanusacerifolia (Aiton) Willdenow. Ciência Florestal, v. 9, n. 2, p.127-136, 1999.

DIAS, J. P. T.; ONO, E. O.; DUARTE FILHO, J. Enraizamento de estacas de brotações oriundas de estacas radiculares de amoreira - preta. Revista Brasileira de Fruticultura, v. 33, n. 1, p.649-653, 2011.

FERREIRA, B. G. A.et al. Metodologias de aplicação de AIB no enraizamento de estacas semilenhosas de Sapium glandulatum (Vell.) Pax. Revista Brasileira de Plantas Medicinais, v. 11, n. 2, p.196-201, 2009.

FISCHER, D. L. O.et al. Enraizamento de estacas semilenhosas de mirtilo sob o efeito de diferentes concentrações de ácido indolbutírico. Revista Brasileira de Fruticultura, v. 30, n. 2, p.557-559, 2008.

HUSSAIN, I.et al. Indole butyric acid and substrates influence on multiplication of blackberry

'Xavante'. Ciência Rural, v. 44, n. 10, p.1761-1765, 2014.

JORGE, L. A. C. Software para análise de fibras e raízes por imagem-SAFIRA. Empresa Brasileira de Pesquisa Agropecuária - Embrapa Instrumentação, São Carlos - SP, 2008.

MAUAD, M. Enraizamento de estacas de azaléia tratadas com concentrações de ANA em diferentes substratos. Ciência e Agrotecnologia, v. 28, n. 4, p.771-777, 2004.

OLIVEIRA, T. P. F.et alEfeito do ácido indol-3-butírico (AIB) no enraizamento de miniestacas de ipêroxo (Handroanthus heptaphyllus Mattos). Ciência Florestal, v. 25, n. 4, p.1043-1051, 2015.

PAULUS, D.; VALMORBIDA, R.; PAULUS, E. Ácido indolbutírico na propagação vegetativa de alecrim. Horticultura Brasileira, v. 34, n. 4, p.520-528, 2016.

PEREIRA, G. H. A.et al. Desenvolvimento de estacas de alamanda amarela sob diferentes concentrações de ácido indolbutírico. Comunicata Scientiae, v. 3, n. 1, p.16-22, 2012.

RSTUDIO. Undelete and data recovery software. Software livre de ambiente de desenvolvimento integrado para $\mathbf{R}$ para análises estatísticas. $R$ version 3.4.1, versão obtida em 30 jun. 2018. Disponível em: https://www.rstudio.com/.

TCHOUNDJEU, Z.et alVegetative propagation of Prunus africana: effects of rooting medium, auxin concentrations and leaf area. Agroforestry Systems, v. 54, n. 3, p.183-192, 2002.

TREVISAN, R.et al. Enraizamento de estacas herbáceas de mirtilo: influência da lesão na base e do ácido indolbutírico. Ciência e Agrotecnologia, v. 32, n. 2, p.402-408, 2008.

VALMORBIDA, J.et al. Enraizamento de estacas de Trichilia catigua A. Juss (catigua) em diferentes estações do ano. Revista Árvore, v. 32, n. 3, p.435-442, 2008.

VÉRAS, M. L. M.et al. Uso de reguladores vegetais na propagação via estaquia de umbucajazeira. Revista de Ciências Agrárias, v. 41, n. 3, p.740-748, 2018.

WENDLING, I. Propagação vegetativa. Colombo: EMBRAPA, 2003. 6 p. 